\title{
An international survey of predictive genetic testing in children for adult onset conditions
}

Rony E. Duncan, BSc (Hons) ${ }^{1-4}$, Julian Savulescu, MBBS, BSc (Med), PhD ${ }^{1,5}$, Lynn Gillam, PhD, ${ }^{2}$ Robert Williamson, PhD, ${ }^{1,3}$ and Martin B. Delatycki, MBBS, $P h D^{1,3,4,6}$

\begin{abstract}
Purpose: Predictive genetic testing is offered to asymptomatic adults even when there is no effective prophylaxis or treatment. Testing of young people in similar circumstances is controversial, and guidelines recommend against it. We sought to document descriptive examples of the occurrence of genetic testing in young people for nonmedical reasons, in the countries where guidelines exist. Methods: Clinical geneticists in the USA, Canada, UK, Australia, and New Zealand were surveyed about the occurrence and outcomes of testing in asymptomatic young people for conditions where no prophylaxis or treatment exists and onset is usually in adulthood. Results: Of 301 responses, details were provided of 49 cases where such testing had occurred. The most common condition tested for was Huntington Disease. In 22 cases (45\%), the young person tested was immature, defined as under the age of 14 years. Results were disclosed to only two immature minors and in three cases parents experienced clinically significant anxiety related to how they would pass on information to their gene positive child. In 27 cases (55\%), the young person tested was mature. Results were disclosed to 26 mature minors and it was reported that two individuals experienced an adverse event. Consistent follow-up did not take place and findings represent the minimum frequency of adverse events. The majority of respondents agree with existing guidelines but many believe each case must be considered individually. Conclusion: Clinicians agree with existing guidelines regarding predictive testing in young people, but choose to provide tests for nonmedical reasons in specific cases. Genet
\end{abstract}

Med 2005:7(6):390-396.

Key Words: genetic screening, child, adolescent, health policy

It is now possible to perform genetic tests that will predict, to a greater or lesser degree of certainty, that a person will develop a medical condition at some time in the future. In cases where there is no effective treatment or prophylaxis for the medical condition, for example Huntington Disease (HD), the decision to have a genetic test is especially emotionally fraught and needs to be handled carefully in clinical practice. Predictive genetic testing of young people (under the age of 18 years) in this situation is generally advised against.

The International Huntington Association and the World Federation of Neurology have published a policy statement recommending that the $\mathrm{HD}$ predictive test only be available to

From the ${ }^{1}$ Murdoch Childrens Research Institute, Royal Children's Hospital, Parkville, Victoria, Australia; ${ }^{2}$ The Centre for the Study of Health and Society, Department of Public Health, University of Melbourne, Victoria, Australia; ${ }^{3}$ Department of Paediatrics, The University of Melbourne, Victoria, Australia; ${ }^{4}$ The Bruce Lefroy Centre for Genetic Health Research, Royal Children's Hospital, Parkville, Victoria, Australia; ${ }^{5}$ Oxford Uehiro Centre for Practical Ethics, University of Oxford, United Kingdom; and ${ }^{6}$ Genetic Health Services Victoria, Royal Children's Hospital, Parkville, Victoria, Australia.

Associate Professor Martin Delatycki, Bruce Lefroy Centre for Genetic Health Research, Murdoch Childrens Research Institute, Royal Children's Hospital, Flemington Road, Parkville, 3052, Victoria, Australia.

Received: November 21, 2004.

Accepted: April 8, 2005.

DOI: 10.1097/01.GIM.0000170775.39092.44 "those having reached the age of majority."1,2 The American Society of Human Genetics in combination with the American College of Medical Genetics, the Clinical Genetics Society in the UK, and the Human Genetics Society of Australasia have all since produced similar guidelines. ${ }^{3-5}$ These show consensus in recommending that testing of "immature" minors (minors who are not competent to be involved in the testing process) should not be performed unless testing will provide a medical benefit. Testing of "mature" minors is less controversial. However, all guidelines recommend a default position where even mature minors should be declined testing unless strong justification is presented to the contrary. ${ }^{3-5}$

There are three key arguments against predictive genetic testing in young people. These are that: (1) testing fails to respect the future autonomy of the young person; (2) testing young people breaches confidentiality; and (3) testing may cause psychosocial harms. ${ }^{6}$ Some of the potential harms that may occur as a result of testing young people involve the wider family. These include alterations to the family dynamic and the bond between parents and children. ${ }^{7}$ Other harms may be more specific to the young person tested, such as feelings of inadequacy or loss of self-esteem. ${ }^{8,9}$ Stigmatization and discrimination, especially in the employment and insurance sector, are also possible. ${ }^{6}$ 
There is limited empirical evidence about effects of predictive genetic testing in young people for adult-onset conditions. The bulk of evidence available revolves around tests that have been performed for medical benefit (e.g., testing for familial adenomatous polyposis). ${ }^{10-13}$ Neither the guidelines opposing testing, nor the arguments in favor of testing, are supported by empirical evidence.

There have been two key surveys published that sought to answer questions about the occurrence of predictive genetic testing in young people. The first survey reported results about the incidence of genetic testing in children in Britain. ${ }^{3}$ This survey found that widespread genetic testing of children was occurring, but that the majority of tests reported were performed because the condition usually manifests in childhood, or because it was necessary for good medical practice. Not a single case was reported of testing a young person for a strictly adult-onset condition (for example, HD). The second survey reported the incidence of genetic testing in asymptomatic young people, as disclosed by laboratories in the USA. ${ }^{14}$ This survey demonstrated that many laboratories offering testing for "later-onset" disorders were performing such testing for asymptomatic young people. Testing had been performed for 13 different conditions, including HD, Charcot-Marie-Tooth disease, and Myotonic Dystrophy. Although this survey provided important information about the occurrence of testing, it did not provide details about the psychosocial impact of testing on young people.

Our study aimed to accomplish the following: (1) document examples of the occurrence of genetic testing in young people for nonmedical reasons, in the countries where guidelines exist; (2) gain information about the psychosocial outcomes of such testing; and (3) gain information about clinical geneticists' reasons for providing or refusing tests and their opinions of existing guidelines.

\section{METHODS}

All members of the following associations who had e-mail addresses were invited to participate in the web-based survey between June and September 2003: the American Society of Human Genetics (ASHG) (Medical Doctors only), the Australasian Association of Clinical Geneticists (AACG), and the Clinical Genetics Society (CGS) of the UK. Completed surveys were received as anonymous e-mails. One reminder notice was sent to all potential participants. The survey was aimed at clinical geneticists as it was assumed most cases of genetic testing in young people would involve a clinical geneticist. Ethics Committee approval was received from the Royal Children's Hospital, Melbourne.

The survey was validated in three stages. Stage one involved a preliminary questionnaire sent to 10 clinical geneticists to gain information about inclusion criteria. Stage two involved content validation by an expert panel who commented on and revised the survey. The panel consisted of two clinical geneticists, two ethicists, a molecular geneticist, an epidemiologist, a genetic counselor, a genetics education researcher with exper- tise in questionnaire design, and a lay person. Finally, the survey was piloted on Australasian participants prior to subsequent participants being invited to respond.

The survey consisted of 17 questions in both forced-choice and short answer formats (http://www.mcri.edu.au/pages/ Rony/Questionnaire2.asp?). Clinicians were asked to identify any cases in which they had provided a predictive genetic test, for a condition that can have its onset in adulthood and could not be treated or prevented, to someone under the age of 18 years who was asymptomatic. Clinicians were then asked to provide details of these cases, including the way in which follow-up had occurred (if at all) and what this follow-up had shown.

The survey was sent to 1732 members of the ASHG, 98 members of the AACG, and 400 members of the CGS. The ASHG was not able to provide us with information on how many of their members were Clinical Geneticists, thus when calculating the response rate for ASHG members, we used the total number of medical doctors as the denominator in the knowledge that this underestimates the clinical geneticists' response rate.

Analysis of the survey was both quantitative and qualitative. Quantitative analysis was performed using SPSS 11.5 (Statistical Program for the Social Sciences, SPSS Inc, Chicago) for descriptive statistics.

Qualitative analysis occurred in 2 phases. Firstly, in order to ensure that the tests reported were performed for nonmedical reasons, as opposed to medical reasons, clinicians' reasons for providing each test were analyzed. This analysis was performed by a clinical geneticist (MBD). Medical reasons for tests included a suspicion of symptoms in the young person and the availability of prophylaxis in the event of a gene-positive result. For this reason, although some of the conditions we report on can have their onset in childhood, we only report on tests performed for nonmedical reasons where onset can be in adulthood.

The second phase of qualitative analysis consisted of two researchers (RED and MBD) independently coding the four major areas covered by the survey. These areas and the codes generated were as follows: (1) Clinicians' reasons for providing the tests. [Codes generated were as follows: (a) to plan for the future; (b) to resolve uncertainty; (c) because of reproductive reasons (including that the person being tested was pregnant, their partner was pregnant, or they planned on starting a family in the near future); (d) to resolve parental anxiety (or because parents had requested the test); and (e) the test was performed prenatally.] (2) The outcomes of the test, as identified through follow-up. [Codes generated were (a) positive event, (b) adverse event, and (c) neutral event.] In analyzing this data, an adverse event was defined as any outcome that is potentially negative for the individual involved, a positive event was defined as any outcome that is potentially beneficial for the individual involved, and a neutral event was defined as any outcome that was not adverse or beneficial. (3) Clinicians' reasons for refusing such tests. [Codes generated were as follows: (a) in order to protect the autonomy of the young person; (b) coun- 
seling resolved the issue; (c) in order to prevent harm; (d) there was no medical benefit to the test; (e) because of policy; and (f) because of privacy.] (4) Clinicians' justifications for the views they hold about existing guidelines. [Codes generated were as follows: (a) it's a case-by-case decision; (b) it's about weighing up benefit and harm; (c) it's not the clinician's decision, it should be up to the family involved; (d) the guidelines are logical; and (e) we need to protect the autonomy of young people.]

A distinction must be made between testing immature young people, who are too young to be involved in the testing process, and mature young people (who are competent to be involved). We have chosen the age of 14 years at which to make this distinction, based on guidelines published by the Society for Adolescent Medicine and recent literature that asserts young people have decision-making capacity comparable to adults from the age of 14 years. ${ }^{15-19}$ From herein, we refer to young people 14 years of age or older as mature young people and those under this age as immature young people.

\section{RESULTS}

We received 347 responses from ASHG members (20\% response rate), 41 responses from AACG members ( $42 \%$ response rate), and 84 responses from CGS members (21\% response rate), giving an overall response rate of $21 \%$. Of these 472 responses, 301 respondents indicated that they were professionally involved in predictive genetic testing, and thus these 301 responses were analyzed in detail. Tables 1 and 2 present the job titles and countries of employment for these 301 respondents. A small proportion of respondents were genetic counselors. We assume this was due to the survey being passed on.

Thirty-six clinicians (12\%) had been involved in the provision of predictive genetic testing on asymptomatic young people for conditions that can have their onset in adulthood and where no treatment or prophylaxis exists. They gave details of 49 cases covering 14 different conditions. Twenty-two of these cases involved immature young people (45\%), whereas 27 involved mature young people (55\%).

\section{Occurrence of testing}

\section{Immature young people}

Table 3 presents a summary of the 22 cases where immature young people underwent testing. Four tests were prenatal tests

Table 1

Respondents' job title

\begin{tabular}{lc}
\hline Job title & Proportion of respondents \\
\hline Clinical geneticist & $254(84 \%)$ \\
Genetic counsellor & $12(4 \%)$ \\
Other (eg. neurologist, pediatrician) & $18(6 \%)$ \\
Job title not given & $17(6 \%)$ \\
\hline
\end{tabular}

Table 2

Respondents' country of employment

\begin{tabular}{lc}
\hline $\begin{array}{l}\text { Country of } \\
\text { employment }\end{array}$ & Proportion of respondents \\
\hline USA & $178(59 \%)$ \\
UK & $62(21 \%)$ \\
Australia & $30(10 \%)$ \\
Canada & $3(1 \%)$ \\
New Zealand & $3(1 \%)$ \\
Other & $8(3 \%)$ \\
Country not given & $17(6 \%)$ \\
\hline
\end{tabular}

where, following an increased risk result, the pregnancy was continued.

There were several nonmedical reasons for provision of tests. The most common reason for testing was because parents wanted to know, with 10 respondents (45\%) citing such a reason: "Parent had suffered through years of misdiagnosis unable to succeed in sports though otherwise asymptomatic, wanted to avoid this for child."

Three respondents (14\%) cited the opportunity for future planning as a reason: "Preparation for the future."

\section{Mature young people}

Table 4 presents a summary of the 27 cases where mature young people underwent testing. All mature young people had results disclosed to them except for one young person who was intellectually disabled (aged 14 years).

There were several nonmedical reasons for provision of tests to mature young people. The most common reason for testing was to resolve uncertainty for the young person, with 13 respondents (48\%) citing this as a reason: "The patient was obsessed with knowing if he was affected."

Seven of these requests were made by the young person alone and six requests were made by the young person and his or her parents together. Six respondents $(21 \%)$ cited the opportunity for future planning as a reason for test provision: "To plan life and career appropriately."

Three of these requests were made by the both the young person and his or her parents, two requests were made by the parents alone and one request was made by the young person alone. Two respondents (7\%) provided tests because of parental anxiety: "Parents wanted to know status. 16 year old was not averse but ++++ pressure from mother."

Both of these requests were made by the parents alone. Two respondents (7\%) also provided tests due to reproductive reasons: "partner pregnant."

One of these requests was made by the young person alone and the other request was made by both the young person and her parents. 
Table 3

Details of the 22 cases in which tests were performed on asymptomatic immature young people (under 14 years of age) for adult-onset disorders

\begin{tabular}{|c|c|c|}
\hline \multirow[t]{4}{*}{ Age of person tested } & Prenatal test & $4(18 \%)$ \\
\hline & $0-4$ years & $8(36 \%)$ \\
\hline & $5-9$ years & $9(41 \%)$ \\
\hline & $10-14$ years & $1(6 \%)$ \\
\hline \multirow[t]{3}{*}{ Gender of person tested } & Female & $7(32 \%)$ \\
\hline & Male & $13(59 \%)$ \\
\hline & No response & $2(9 \%)$ \\
\hline \multirow[t]{11}{*}{ Condition tested for } & Huntington Disease & $4(18 \%)$ \\
\hline & Myotonic Dystrophy & $4(18 \%)$ \\
\hline & Charcot-Marie Tooth & $3(14 \%)$ \\
\hline & Becker Dystrophy & $2(9 \%)$ \\
\hline & Von Hippel Lindau & $2(9 \%)$ \\
\hline & Spinocerebellar Ataxia & $2(9 \%)$ \\
\hline & Dystonia & $1(6 \%)$ \\
\hline & Friedreich Ataxia & $1(6 \%)$ \\
\hline & Kennedy Disease (SBMA) ${ }^{a}$ & $1(6 \%)$ \\
\hline & MODY $^{b}$ & $1(6 \%)$ \\
\hline & FSHD $^{c}$ & $1(6 \%)$ \\
\hline \multirow[t]{3}{*}{ Results of test } & Increased risk & $12(55 \%)$ \\
\hline & Decreased risk & $9(41 \%)$ \\
\hline & Don’t know & $1(6 \%)$ \\
\hline \multirow[t]{3}{*}{ Test requested by } & Parent(s) or guardian(s) & $18(82 \%)$ \\
\hline & Other (details not given) & $2(9 \%)$ \\
\hline & No response & $2(9 \%)$ \\
\hline \multirow{3}{*}{$\begin{array}{l}\text { Was result disclosed to individual } \\
\text { who was tested? }\end{array}$} & Yes & $2(9 \%)$ \\
\hline & No & $14(64 \%)$ \\
\hline & Don’t know & $6(27 \%)$ \\
\hline \multirow[t]{4}{*}{ Has follow up occurred? } & Yes & $11(50 \%)$ \\
\hline & No & $9(41 \%)$ \\
\hline & Don’t know & $1(6 \%)$ \\
\hline & No response & $1(6 \%)$ \\
\hline $\begin{array}{l}\text { Has an adverse event occurred for } \\
\text { the young person tested? }\end{array}$ & Yes & 0 \\
\hline $\begin{array}{l}\text { Has an adverse event occurred for } \\
\text { the parents involved? }\end{array}$ & Yes & $3(14 \%)$ \\
\hline
\end{tabular}

${ }^{a}$ SBMA, Spinal Bulbar Muscular Atrophy.

${ }^{b}$ MODY, Maturity Onset Diabetes of the Young.

${ }^{c}$ FSHD, Fascio Scapulo Humeral Dystrophy.

\section{Effects of testing}

\section{Immature young people}

Of the 22 cases reported where an immature young person had predictive genetic testing, 11 cases have been followed up $(50 \%)$. Follow up occurred in varied ways, from a single phone call to regular contact for 6 months. Follow-up was conducted
Table 4

Details of the 27 cases in which tests were performed on asymptomatic mature young people (14 years of age and older) for adult-onset disorders

\begin{tabular}{|c|c|c|}
\hline \multirow[t]{2}{*}{ Age of person tested } & $14-15$ years & $9(33 \%)$ \\
\hline & $16-17$ years & $18(67 \%)$ \\
\hline \multirow[t]{2}{*}{ Gender of person tested } & Female & $16(59 \%)$ \\
\hline & Male & $11(41 \%)$ \\
\hline \multirow[t]{6}{*}{ Condition tested for } & Huntington Disease & $14(52 \%)$ \\
\hline & Myotonic Dystrophy & $5(19 \%)$ \\
\hline & Breast Cancer (BRCA1 \& 2) & $3(11 \%)$ \\
\hline & $\mathrm{FSHD}^{a}$ & $2(7 \%)$ \\
\hline & Spinocerebellar Ataxia & $2(7 \%)$ \\
\hline & $\begin{array}{l}\text { Balanced Translocation } \\
\text { associated with manic- } \\
\text { depressiveness }\end{array}$ & $1(4 \%)$ \\
\hline \multirow[t]{4}{*}{ Results of test } & Increased risk & $9(33 \%)$ \\
\hline & Decreased risk & $16(59 \%)$ \\
\hline & Don't know & $1(4 \%)$ \\
\hline & No response & $1(4 \%)$ \\
\hline \multirow[t]{3}{*}{ Test requested by } & Parent(s) & $4(15 \%)$ \\
\hline & Young person & $10(37 \%)$ \\
\hline & $\begin{array}{l}\text { Both Parent(s) and young } \\
\text { person }\end{array}$ & $13(48 \%)$ \\
\hline \multirow{2}{*}{$\begin{array}{l}\text { Was result disclosed to individual } \\
\text { who was tested? }\end{array}$} & Yes & $26(96 \%)$ \\
\hline & No & $1(4 \%)$ \\
\hline \multirow[t]{3}{*}{ Has follow up occurred? } & Yes & $18(67 \%)$ \\
\hline & No & $8(30 \%)$ \\
\hline & Don't know & $1(4 \%)$ \\
\hline $\begin{array}{l}\text { Has an adverse event occurred for } \\
\text { the young person who was } \\
\text { tested? }\end{array}$ & Yes & $2(7 \%)$ \\
\hline $\begin{array}{l}\text { Has an adverse event occurred for } \\
\text { the parents involved? }\end{array}$ & Yes & 0 \\
\hline
\end{tabular}

${ }^{a}$ FSHD, Fascio Scapulo Humeral Dystrophy.

by a range of professionals including counselors, psychologists, and clinical geneticists.

There were no reports of adverse events in immature young people who were tested, although only two were reported as having been informed of test results.

There were three cases of an adverse event for the parents of immature young people who were tested. Two adverse events followed prenatal increased risk results for HD, where parents decided to continue the pregnancy. The third adverse event followed an increased risk result for Dystonia in an 8-year-old male. It was reported in all three cases that parents felt distressed by the information they had and were feeling anxious about how and when to tell their child.

There was one report of a beneficial effect for the parents of an immature young person who was tested: "parent relieved, child seemed to have forgotten about the test." 


\section{Mature young people}

Of the 27 cases reported where a mature young person had predictive genetic testing, 18 cases have been followed up (67\%). Follow-up occurred in varied ways.

Two adverse events were reported in mature young people who underwent testing. One adverse event followed an increased risk result for HD in a 17-year-old male: "Initial depression and rebellion but eventual acceptance."

The other adverse event followed a decreased risk result for HD in a 17-year-old female: "No psychological disturbance but worry and responsibility for affected mother and untested brothers."

There were also nine reports of beneficial effects. Six followed decreased risk results: "Enabled him to focus on school, etc., and parents say behavior improved and he deals with difficulties in more mature way.”

And three followed increased risk results: "So far she is doing fine and seems to have integrated this information into her thoughts about her future in a healthy way."

\section{Refusals to provide testing}

Of the 301 respondents involved in testing, 159 (53\%) had refused to perform a predictive genetic test for a condition where no treatment or prophylaxis exists and where the person to be tested was an asymptomatic young person. These professionals, together, have refused such testing on over 800 separate occasions. Respondents gave several reasons for their refusals to provide testing, often citing more than one reason. The most common reason was to protect the autonomy of the young person. This was cited by 75 respondents (47\%): "Wanted to wait until kids were old enough to make their own choices about testing."

Fifty-three respondents (33\%) refused testing because it did not provide a medical benefit: "No perceived medical benefit for the individual or family for the testing."

Twenty-three respondents (14\%) refused testing because of a possibility of harm: "Potential harm to the child. . for example. . .father wanted to know if either of his daughters had a breast cancer gene so he could send the other to college."

Eight respondents (5\%) cited policy as a reason: "The clinical scenario did not meet the guidelines for testing established for patients at risk of Huntington Disease."

Eight respondents (5\%) cited that counseling had resolved the issue: "I think refused is too strong a word. The family were demanding testing, I simply went over the reasons for not testing. Once they had thought things through the family made their own decision not to test."

And one respondent (1\%) cited privacy as a reason: "Primary concern was privacy of genetic information."

\section{Views on existing guidelines}

Table 5 presents respondents' views of the guidelines. Reasons for these views were provided by 230 respondents. The most common justification cited for respondents' views on the guidelines, regardless of their specific view, was that each case
Table 5

Respondents' views on guidelines concerning predictive genetic testing in young people

\begin{tabular}{lc}
\hline Extent of Agreement with Guidelines & $\begin{array}{c}\text { Proportion of respondents who } \\
\text { feel this way }\end{array}$ \\
\hline Strongly agree & $104(35 \%)$ \\
Agree & $141(47 \%)$ \\
Don't know & $10(3 \%)$ \\
Disagree & $15(5 \%)$ \\
Strongly disagree & $5(2 \%)$ \\
No response & $26(9 \%)$ \\
\hline
\end{tabular}

needs to be considered individually. Of the 230 respondents who provided a reason for their view, 99 respondents (43\%) cited this as a justification: "I don't believe in a rigid cut-off age. . . as I believe obtaining maturity to gain informed consent is a gradual process."

Eighty-eight respondents (38\%) cited the need to protect autonomy as a justification: "Feel the decision should be up to the individual and question the ability for a minor to truly make the decision if parents involved."

Seventy-four respondents (32\%) cited the weighing up of benefit and harm as a justification: "I think it can only add anxiety, has no benefit."

Thirty-four respondents (15\%) cited logic of the guidelines as a justification: "Because the guidelines are right"

And nine respondents (4\%) justified their views with a statement about the inappropriateness of clinicians (as opposed to the families) making these decisions: "It is up to the family to decide and not us. Refusing testing is paternalistic."

\section{DISCUSSION}

Table 6 summarizes the six key findings of this study.

1. We document 49 cases in which predictive genetic testing in young people has occurred for nonmedical reasons

Twenty-two (45\%) of these were tests involving immature young people and 27 (55\%) were tests involving mature young

Table 6

Key findings

1. We have documented 49 cases in which predictive genetic testing in young people has occurred for nonmedical reasons

2. We found evidence of two adverse events in young people who were tested

3. We found three instances of clinically significant parental anxiety relating to how and when to disclose a positive test result to their immature child

4. Professionals refuse a high number of requests to perform predictive genetic testing in young people for nonmedical reasons

5. Consistent follow-up is not occurring in cases where such testing is performed

6. The majority of respondents agree with the existing guidelines, but feel that each case needs to be assessed individually 
people. This is the largest and most descriptive collection of such case-studies. Some clinicians are evidently accepting nonmedical justifications for testing, implying that they believe there are benefits other than purely medical benefits associated with having knowledge of future health. Unfortunately, given the low rates of up-take, we are unable to make any inferences about current practice more generally. It must also be emphasized that details of the 49 case-studies we describe were provided by clinicians, not the individuals who underwent testing themselves. As these descriptions are second-hand accounts, they are thus less accurate than first-hand accounts.

\section{We found evidence of two adverse events in young people who were tested}

This constitutes a rate of $7.1 \%$ across the 28 cases in which the young person was informed of the result and follow-up occurred. We have defined an adverse event as any outcome that is potentially negative for the individual involved.

The rates of adverse events we report are the minimum frequency of adverse events possible for this group. This is due to four reasons. Firstly, clinicians were asked to provide details of test outcomes in cases where they provided tests, contrary to recommendations made in current guidelines. Although the survey was anonymous, it is possible that clinicians underreported adverse events. Secondly, follow-up did not occur in many cases and in those that it did, it was not systematic (see point 5 ). This means that there may have been additional adverse events that were not known about. Thirdly, there were only two known disclosures of test results to the 22 immature young people who were tested. Thus, in the majority of these cases, it is too early to draw any conclusions about the impact of testing. Lastly, the survey was administered electronically, and this may have contributed to under-reporting. For example, some individuals may have been unsure about completing a survey online.

A study concerning the outcomes of predictive genetic testing for $\mathrm{HD}$ in adults reported that 44 of 202 individuals (21.8\%) experienced adverse events. ${ }^{20}$ This research also reported that $1.98 \%$ of individuals suffered catastrophic events (psychiatric hospitalization, attempted suicide, or committed suicide), which is similar to the previously reported frequency of $0.97 \%{ }^{21}$ Together, this research describes psychological consequences in the largest known predictive testing cohort for the longest period of time (up to 5 years).

It is also important to recognize, in addition to the adverse outcomes of testing, the several positive effects of predictive genetic testing in young people reported.

\section{We found $\mathbf{3}$ instances of clinically significant parental anxiety relating to how and when to disclose a positive test result to their immature child}

This constitutes a rate of $27 \%$ across the 11 cases in which follow-up occurred. This reveals a need to include discussion of such risks not only when counseling parents about testing of immature children but also when counseling parents about prenatal tests, in case parents decide to continue with their pregnancy. This also highlights the differences between testing mature and immature minors and the different issues that arise. Issues related to parental disclosure to the young person are essentially specific to situations where the minor is too young to be actively involved in the testing process.

\section{Professionals refuse a high number of requests to perform predictive genetic testing in young people for nonmedical reasons}

Clinicians reported that they had refused testing on over 800 separate occasions. Such tests are therefore refused far more frequently than they are performed. However, the term "refuse" can be difficult to define. A refusal, as reported, may not necessarily indicate that a young person or family was turned away after seeking testing. It may indicate that the issue was raised and that, following discussion, both the clinician and client agreed that not testing the young person was the preferred option.

\section{Consistent follow-up is not occurring in cases where such testing is performed}

This is of concern given the minimal evidence that exists about the effects of such testing. It is also noteworthy as it means the statistics we quote about adverse events are the minimum frequency, given that cases have not been followed-up systematically or in some cases at all. The evidence available about effects of predictive genetic testing in young people revolves solely around tests that have been performed for medical benefit. ${ }^{13}$ We believe that this is a useful place to begin, shedding some light on testing for nonmedical reasons, but find it frustrating that we have evidence of 49 cases where testing was performed for nonmedical reasons, where no systematic follow-up was performed. Calls for systematic research in this field have been made before. ${ }^{3,4,22-26}$ We reiterate these here.

\section{The majority of respondents agree with the existing guidelines, but feel that each case needs to be assessed individually}

It is worth noting that although the majority of respondents agree with existing guidelines, only $15 \%$ cited policy as a reason for refusing such tests. This indicates that clinicians are making individual clinical judgments, as opposed to simply following suggested recommendations.

We do not believe that clinicians are acting unethically in providing predictive genetic tests to young people, nor that they are acting in ignorance of the existing guidelines. Clinicians agree with existing guidelines regarding predictive testing in young people, but choose to provide tests for nonmedical reasons in specific cases. Their reasons for doing so in these cases (or not doing so in other cases) are highly varied and depend on the details of each individual case.

\section{ACKNOWLEDGMENTS}

We thank the study respondents and the British Society of Human Genetics and the American Society of Human Genetics for their assistance in disseminating the survey to their members. We are also grateful to Ros Tassicker for comments 


\section{Duncan et al.}

on the survey. This research was funded through an Australian Postgraduate Award. All authors declare that they have no competing interests. M.B.D. is the recipient of a National Health and Medical Research Council Practitioner Fellowship. Ethics Committee approval was obtained from the Royal Children's Hospital, Melbourne, Victoria.

\section{References}

1. International Huntington Association and the World Federation of Neurology Research Group on Huntington's Chorea. Ethical issues policy statement on Huntington's disease molecular genetics predictive test. J Med Genet 1990;27:34-38.

2. International Huntington Association and the World Federation of Neurology Research Group on Huntington's Chorea. Guidelines for the molecular genetics predictive test in Huntington's disease. J Med Genet 1994;31:555-559.

3. Clin Genet Society. The genetic testing of children. Working Party of the Clin Genet Society (UK). J Med Genet 1994;31:785-97.

4. American Society of Human Genetics BoD, American College of Medical Genetics BoD. Points to Consider: Ethical, Legal and Psychosocial Implications of Genetic Testing in Children and Adolescents. Am J Hum Genet 1995;57:1233-1241.

5. Human Genetics Society of Australasia. Predictive Testing in Children and Adolescents: Human Genetics Society of Australasia, 2003

6. Clarke A, Flinter F. The genetic testing of children: a clinical perspective. In: Marteau T, Richards M, eds. The troubled helix: Social and psychological implications of the new human genetics. Cambridge: Cambridge University Press, 1996:164-176.

7. Wertz DC, Fanos JH, Reilly PR. Genetic testing for children and adolescents: Who decides? JAMA 1994;272:875-81.

8. Holland J. Should parents be permitted to authorize genetic testing for their children. Family Law Quarterly 1997;31:321-353.

9. Meiser B, Gleeson MA, Tucker KM. Psychological impact of genetic testing for adult-onset disorders: An update for clinicians. MJA 2000;172:126-129.

10. Codori AM, Petersen GM, Boyd PA, Brandt J, Giardiello FM. Genetic testing for cancer in children. Short-term psychological effect. Arch Pediatr Adolesc Med 1996; 150:1131-8.
11. Michie S, McDonald V, Bobrow M, McKeown C, Marteau T. Parents responses to predictive genetic testing in their children: Report of a single case study. J Med Genet 1996;33:313-318.

12. Michie S, Bobrow M, Marteau TM. Predictive genetic testing in children and adults: a study of emotional impact. J Med Genet 2001;38:519-26.

13. Codori AM, Zawacki KL, Petersen GM et al. Genetic testing for hereditary colorectal cancer in children: long-term psychological effects. Am J Med Genet 2003;116A:11728.

14. Wertz DC, Reilly PR. Laboratory policies and practices for the genetic testing of children: A survey of the helix network. Am J Hum Genet 1997;61:1163-1168.

15. Weithorn LA, Campbell SB. The competency of children and adolescents to make informed treatment decisions. Child Dev 1982;53:1589-98.

16. Petersen AC, Leffert N. Developmental Issues Influencing Guidelines for Adolescent Health Research: A Review. J Adolesc Health 1995;17:298-305.

17. Toner K, Schwartz R. Why a teenager over Age 14 should be able to consent, rathe than merely assent, to participation as a human subject of research. Am J Bioeth 2003;3:38-40.

18. Santelli JS, Smith Rogers A, Rosenfeld WD, et al. Guidelines for Adolescent Health Research: A position paper for the society of adolescent medicine. J Adolesc Health 2003;33:396-409.

19. Sanci L, Sawyer SM, Weller PJ, Bond LM, Patton GC. Youth health research ethics: time for a mature-minor clause. MJA 2004;180:336-338.

20. Almqvist E, Brinkman R, Wiggins S, Hayden M. Psychological consequences and predictors of adverse events in the first 5 years after predictive testing for Huntington's disease. Clin Genet 2003;64:300-309.

21. Almqvist EW, Bloch M, Brinkman R, Craufurd D, Hayden MR. A Worldwide Assessment of the Frequency of Suicide, Suicide Attempts, or Psychiatric Hospitalisation after Predictive Testing for Huntington Disease. Am J Hum Genet 1999;64: 1293-1304.

22. Michie S, Marteau TM. Predictive genetic testing in children: The need for psychological research. Br J Health Psychol 1996;1:3-14.

23. Bloch M, Hayden MR. Opinion: Predictive testing for Huntington Disease in childhood: challenges and implications. Am J Hum Genet 1990;46:1-4

24. Marteau TM. The genetic testing of children. J Med Genet 1994;31:743.

25. Michie S. Predictive testing in children: paternalism or empiricism? In: Marteau T, Richards M, eds. The troubled helix: Social and psychological implications of the new human genetics. Cambridge: Cambridge University Press, 1996:177-186.

26. Fryer A. The genetic testing of children. J R Soc Med 1997;90:419-421. 